\title{
Air pollution by coal dust as a factor of ecological compatibility for coal mining enterprises
}

\author{
Tatiana Korchagina ${ }^{1, *}$, Anatoly Bykov ${ }^{2}$, and Evgeny Schastlivcev ${ }^{2}$ \\ ${ }^{1}$ LLC "Mining Engineering Institute of Siberia" of JSC UHC "SDS-Ugol" \\ ${ }^{2}$ Kemerovo Branch of Institute of computing technologies SB RAS, 650025, Kemerovo, Russia
}

\begin{abstract}
Coal mining enterprises (there are more than 130 in the Kemerovo region), are powerful sources of pollutant emissions (P) into the atmosphere. They account for almost a third of the total mass of the cumulative annual emissions in the region. A significant number of coal mining enterprises are located in the vicinity of the boundaries of residential settlements of Kuzbass. At the same time, emissions of coal mining enterprises are mainly carried out from unorganized sources of air pollution (SAI), which do not have treatment facilities. All this leads to pollution of the surface air layer by the coal mining industry. Currently, the category of the enterprise is determined only by its economic activity associated with the production of a product. In particular, all coal-mining enterprises, including the extraction and enrichment of coal, anthracite and brown coal, are classified as category 1 enterprises, i.e. enterprises with significant negative environmental impact (NEI) and related to the areas of application of the best available technologies (BAT). However, this approach to the definition of the category does not take into account the individual characteristics of the enterprise and the level of ecological compatibility of its production.
\end{abstract}

\section{Introduction}

Coal mining enterprises have a number of characteristic production processes that generate identical emissions into the atmosphere [1-6]. Its include drilling and blasting operations, coal loading and transportation, dusty coal warehouses and dumps, ventilation installations, quarry transport. In all these processes, coal dust (code 3749) is the most characteristic and unique $\mathrm{P}$ for coal mining enterprises. Therefore, we assume that the pollution of the atmosphere by coal dust can be an indicator of the level of ecological compatibility in the coal mining enterprise as a whole. For the integral evaluation of all the characteristics of atmospheric pollution with coal dust offers the option $S_{p}$ (ha/tons) representing the area $S$ (ha/ $\mathrm{kt}$ ) the zone of influence of emissions of the plant of coal dust divided by the annual output $\mathrm{M}(\mathrm{kt})$ coal company. To determine this indicator, it is enough to include coal dust in the composition of the calculated SV and determine the area of the zone of influence.

\footnotetext{
* Corresponding author: t.korchagina@sds-ugol.ru
} 
According to [2] the zone of influence of emissions at the enterprise for a given $\mathrm{P}$ is defined as an area within which $\mathrm{C}_{\mathrm{s}}>0.05 \mathrm{Mpcr}$, where $\mathrm{C}_{\mathrm{s}}(\mathrm{mg} / \mathrm{m} 3)$ is the maximum (in terms of wind speeds and directions) single concentration of this $\mathrm{P}$, and $\mathrm{PC}_{\mathrm{s}}(\mathrm{mg} / \mathrm{m} 3)-$ the corresponding single maximum permissible concentration (for coal dust $\mathrm{PC}_{\mathrm{s}}=0.3 \mathrm{mg} / \mathrm{m} 3$ ). The distribution of Cs on the territory is determined by the calculation of air pollution on the basis of the normative methodology MRR-2017 [5] using unified programs for calculating air pollution [2].

The meaning of the indicator of ecological compatibility of the $S_{p}$ is that it characterizes the size of the area with significant pollution by coal dust per 1000 tons of coal production. When determining the size of the zone of influence is taken into account the power of SAI emissions of the enterprise, their parameters and location on the industrial site, climatic parameters of the territory and the coefficient of relief. This takes into account almost all the parameters that determine the process of air pollution with coal dust. It is also taken into account how from an environmental point of view (dust suppression, humidification) the various stages of mining are organized.

Naturally, the proposed indicator $\mathrm{S}_{\mathrm{p}}$ can be considered informative, if the inventory and the task of the calculated parameters of coal dust for different enterprises are carried out correctly and uniformly. The basis for the inventory of emission sources of coal mining enterprises is the industry methodology [6].

Note one important feature for determining the zone of influence associated with the setting of the settling coefficient of particles for the calculation of [5]. As a rule, in most calculations, project developers do not pay attention to the justification of the settling coefficient $\mathrm{F}$, which takes into account the rate of settling of $\mathrm{P}$ (gases and aerosols, including solid particles) in the atmospheric air. However, as figure 1 shows, at a small distance (up to $1.5 \mathrm{~km}$ ) from an unorganized areal source, the results of calculating the maximum surface concentration vary significantly.

\section{Materials and Methods}

Let us consider in more detail the procedure for selecting the settling coefficient $\mathrm{F}$ before carrying out the calculated estimates of atmospheric pollution by the method [5].

In the framework of the method [5], a dimensionless coefficient $F$ is used in the calculation of atmospheric pollution, taking into account the rate of subsidence of $\mathrm{P}$ (gases and aerosols, including solid particles) in the atmospheric air. When developing projects, in most cases, task F is used on the basis of table 1 taken from Annex 2 to the methodology [5]. According to this table, all dust particles released into the atmosphere without treatment have a settling coefficient $F=3$. In fact, when particle size information is available, the value $O f$ the $\mathrm{F}$ coefficient is set individually for each source, depending on the dimensionless ratio $\mathrm{V}_{\mathrm{g}} / \mathrm{U}_{\mathrm{m}}$, where $\mathrm{Vg}$ is the gravitational settling velocity of the particles.

Table 1. Dependence of the coefficient F on the degree of purification.

\begin{tabular}{|c|c|}
\hline Degree of purification, $\%$ & $\begin{array}{c}\text { Recommended sedimentation } \\
\text { coefficient } \boldsymbol{F}\end{array}$ \\
\hline Over 90 & 2,0 \\
\hline 75 to 90 & 2,5 \\
\hline Less than 75 or no cleaning & 3,0 \\
\hline
\end{tabular}




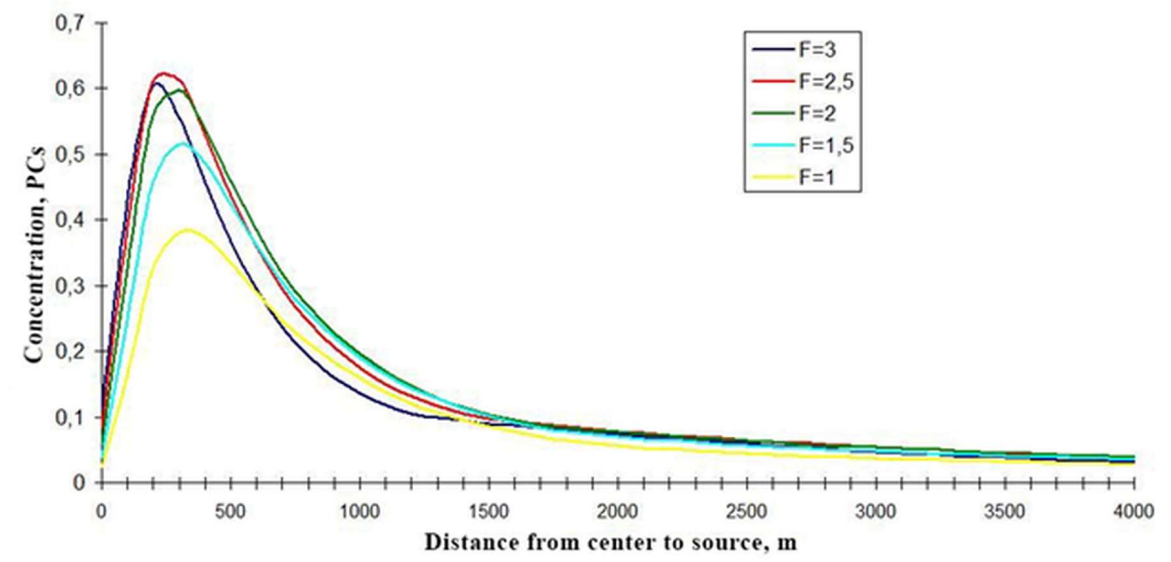

Fig. 1. Effect of the settling coefficient $F$ on the graph of the surface concentration of coal dust (PCs $=0.3 \mathrm{mg} / \mathrm{m} 3$ ) along the axis of the torch from the coal warehouse height and size.

$\mathrm{U}_{\mathrm{m}}-$ dangerous wind speed at which the surface concentration for a given source reaches a maximum (p. 5. 10. from [2]). In this case, the recommendations of Annex 2 of [2] can be summarized in table 2 .

Table 2. Dependence of the coefficient $\mathrm{F}$ on the ratio $\mathrm{Vg} / \mathrm{Um}$.

\begin{tabular}{|c|c|}
\hline $\boldsymbol{V}_{\boldsymbol{g}} / \boldsymbol{U}_{\boldsymbol{m}}$ & Sedimentation coefficient $\boldsymbol{F}$ \\
\hline$\leq 0,015$ & 1,0 \\
\hline $0,015<V_{g} / U_{m} \leq 0,03$ & 1,5 \\
\hline$>0,03$ & $\begin{array}{c}2,0-3,0 \text { taking into account the degree of } \\
\text { purification given in table 1 }\end{array}$ \\
\hline
\end{tabular}

If the diameter of the particles $\mathrm{D}$ does not exceed 100 microns, the settling rate of the particles Vg can be found [7] using the Stokes formula:

$$
V_{g o}=\frac{10^{-8} \cdot g \cdot R o \cdot D^{2}}{18 \eta}
$$

where $\mathrm{V}_{\mathrm{go}}$ is a gravitational subsidence velocity, $\mathrm{cm} / \mathrm{s}$;

$\mathrm{g} \approx 981$ is an acceleration of gravity, $\mathrm{cm} / \mathrm{S} 2$;

$\mathrm{R}_{\mathrm{o}}$ is a particle density, $\mathrm{g} / \mathrm{cm} 3$;

$\eta$ is a dynamic viscosity of air, $\mathrm{g} / \mathrm{cm} \cdot \mathrm{s}$;

$\mathrm{d}_{\mathrm{g}}$ is an aerodynamic diameter of particles, microns.

In the future, instead of $\mathrm{V}_{\mathrm{go}}$, we consider $\mathrm{Vg}=0.01 \mathrm{~V}_{\mathrm{go}}$, which has a dimension of $\mathrm{m} / \mathrm{s}$.

The value of $\eta$ varies slightly within the range of air temperature changes typical for atmospheric pollution calculations (from $-20^{\circ} \mathrm{C}$ to $+20^{\circ} \mathrm{C}$ ) [9]. This change in practice can be neglected and, taking into account that most calculations in accordance with [5] are carried out on summer conditions, it is possible to assume a dynamic viscosity of the air $\eta=1,8 \cdot 10$ - $4(\mathrm{~g} / \mathrm{cm} \cdot \mathrm{s})$, which corresponds to a temperature of $+20^{\circ} \mathrm{C}$.

\section{Results and Discussion}

Most sources of air pollution by dust particles in coal mining enterprises are unorganized, and their emissions do not have an initial flare rise due to the initial velocity and overheating of the gas-air mixture. In particular, the source describing the technological explosion is approached in the calculation by an unorganized source formed after the explosion cloud 
rises to a height where it has lost its initial dynamic characteristics. Any unorganized source, both linear and areal, has a dangerous velocity $U_{m}=0.5 \mathrm{~m} / \mathrm{s}$, which is independent of the deposition coefficient $\mathrm{F}$.

The density of coal varies from 1.20 to $1.5 \mathrm{~g} / \mathrm{cm} 3$, and the density of the rock from 2.5 to $4.5 \mathrm{~g} / \mathrm{cm} 3$. From tables 3 and 4 it is possible to determine the value of the settling coefficient $\mathrm{F}$ for coal particles of different diameters and densities.

Table 3. Ratio of deposition velocity $\mathrm{V}_{\mathrm{g}}(\mathrm{m} / \mathrm{s})$ to hazardous wind velocity $U_{\mathrm{m}}=0.5 \mathrm{~m} / \mathrm{s}$ for an unorganized source depending on particle size $\mathrm{D}(\mu \mathrm{m})$ and coal density $\mathrm{R}_{\mathrm{o}}\left(\mathrm{g} / \mathrm{cm}^{3}\right)$.

\begin{tabular}{|c|c|c|c|c|}
\hline $\mathbf{D}$ & $\mathbf{R}_{\mathbf{0}}=\mathbf{1 , 2}$ & $\mathbf{R}_{\mathbf{0}}=\mathbf{1 , 3}$ & $\mathbf{R}_{\mathbf{0}}=\mathbf{1 , 4}$ & $\mathbf{R}_{\mathbf{0}}=\mathbf{1 , 5}$ \\
\hline 1 & 0,00008 & 0,00009 & 0,0001 & 0,00011 \\
\hline 2 & 0,00031 & 0,00034 & 0,00036 & 0,00039 \\
\hline 3 & 0,00069 & 0,00074 & 0,0008 & 0,00086 \\
\hline 4 & 0,0012 & 0,0013 & 0,0014 & 0,0015 \\
\hline 5 & 0,00186 & 0,00202 & 0,00217 & 0,00233 \\
\hline 6 & 0,00267 & 0,00289 & 0,00312 & 0,00334 \\
\hline 7 & 0,00362 & 0,00392 & 0,00422 & 0,00453 \\
\hline 8 & 0,00471 & 0,00511 & 0,0055 & 0,00589 \\
\hline 9 & 0,00595 & 0,00645 & 0,00695 & 0,00744 \\
\hline 10 & 0,00734 & 0,00795 & 0,00856 & 0,00917 \\
\hline 11 & 0,00887 & 0,0096 & 0,01034 & 0,01108 \\
\hline 12 & 0,01054 & 0,01142 & 0,0123 & 0,01317 \\
\hline 13 & 0,01235 & 0,01338 & 0,01442 & 0,01545 \\
\hline 14 & 0,01431 & 0,01551 & 0,0167 & 0,0179 \\
\hline 15 & 0,01642 & 0,01779 & 0,01916 & 0,02053 \\
\hline 16 & 0,01867 & 0,02023 & 0,02178 & 0,02334 \\
\hline 17 & 0,02106 & 0,02282 & 0,02458 & 0,02634 \\
\hline 18 & 0,0236 & 0,02557 & 0,02754 & 0,02951 \\
\hline
\end{tabular}

Table 4. Ratio of deposition velocity $\mathrm{V}_{\mathrm{g}}(\mathrm{m} / \mathrm{s})$ to hazardous wind velocity $U_{\mathrm{m}}=0.5 \mathrm{~m} / \mathrm{s}$ for an unorganized source depending on particle size $\mathrm{D}(\mu \mathrm{m})$ and rock density Ro $(\mathrm{g} / \mathrm{cm} 3)$

\begin{tabular}{|c|c|c|c|c|c|}
\hline $\mathbf{D}$ & $\mathbf{R o}=\mathbf{2 , 5}$ & $\mathbf{R o}=\mathbf{3 , 0}$ & $\mathbf{R o}=\mathbf{3 , 5}$ & $\mathbf{R o}=\mathbf{4 , 0}$ & $\mathbf{R o}=\mathbf{4 , 5}$ \\
\hline 1 & 0,00018 & 0,00021 & 0,00025 & 0,00028 & 0,00032 \\
\hline 2 & 0,00065 & 0,00079 & 0,00092 & 0,00105 & 0,00117 \\
\hline 3 & 0,00143 & 0,00172 & 0,00201 & 0,0023 & 0,00257 \\
\hline 4 & 0,00251 & 0,00302 & 0,00353 & 0,00403 & 0,00451 \\
\hline 5 & 0,00388 & 0,00469 & 0,00547 & 0,00625 & 0,00699 \\
\hline 6 & 0,00556 & 0,00672 & 0,00784 & 0,00895 & 0,01002 \\
\hline 7 & 0,00755 & 0,00911 & 0,01062 & 0,01214 & 0,01359 \\
\hline 8 & 0,00983 & 0,01186 & 0,01384 & 0,01581 & 0,01769 \\
\hline 9 & 0,01241 & 0,01498 & 0,01747 & 0,01997 & 0,02234 \\
\hline 10 & 0,01529 & 0,01846 & 0,02153 & 0,02461 & 0,02753 \\
\hline 11 & 0,01848 & 0,0223 & 0,02602 & 0,02974 & 0,03327 \\
\hline 12 & 0,02196 & 0,02651 & 0,03093 & 0,03534 & 0,03954 \\
\hline
\end{tabular}




\begin{tabular}{|l|c|c|c|c|c|}
\hline 13 & 0,02575 & 0,03108 & 0,03626 & 0,04144 & 0,04636 \\
\hline 14 & 0,02984 & 0,03601 & 0,04201 & 0,04802 & 0,05372 \\
\hline 15 & 0,03423 & 0,0413 & 0,04819 & 0,05508 & 0,06162 \\
\hline 16 & 0,03892 & 0,04696 & 0,05479 & 0,06262 & 0,07006 \\
\hline
\end{tabular}

Using data from the classification table for automatic partitioning of total dust emissions by fractional composition [3], we determined the dispersed composition of dust particles emitted into the atmosphere for the main processes of coal mining (table 5).

A comparison of table 5 with tables 3 and 4 shows that $98 \%$ of the particles are less than 10 microns in size when blown off the dumps, so the settling coefficient can be taken for coal as $\mathrm{F}=1.0$ and for rock $\mathrm{F}=1.5$. During blasting, $70 \%$ of particles with a diameter of less than 10 microns are carried outside the cut (large particles settle in the quarry), so it is advisable to represent the explosion emission in the form of two sources, where the first $(70 \%$ of the emission) has a coefficient $\mathrm{F}=1.0$, and the second ( $30 \%$ of the emission) $\mathrm{F}=2.0$. For rock dust coefficient $F$ should be taken 1.5 and 2.5 , respectively.

Table 5. Division of total dust emissions by fractional composition.

\begin{tabular}{|c|c|c|c|c|c|c|c|c|}
\hline & \multicolumn{7}{|c|}{ Particle size class, $\boldsymbol{\mu m}$} \\
\hline Code & Source type & $0-5$ & $5-10$ & $10-20$ & $20-30$ & $30-50$ & $50-100$ & $>100$ \\
\hline 101 & Blasting & 50 & 20 & 15 & 10 & 4 & 0,9 & 0,1 \\
\hline 201 & $\begin{array}{c}\text { Blowing from the } \\
\text { dump }\end{array}$ & 95 & 3 & 0.9 & 0.1 & & & \\
\hline 301 & Loading of coal & 6 & 8 & - & 31 & 54 & - & - \\
\hline 501 & Crushing of rock mass & 20 & 30 & 35 & 13 & $2-$ & 0 & - \\
\hline
\end{tabular}

The above estimates with the calculation of Vg according to Stokes law refer to the settling of particles in the resting air (in the research chamber or indoors). In the real atmosphere, dynamic and thermal factors are always present at the boundary with the underlying surface, where the propagation of $\mathrm{P}$ occurs, generating turbulence, under the influence of which the rate of subsidence can change. However, it is quite difficult to estimate the real limits of the change, because the data of standard meteorological observations are absolutely insufficient for the calculation of turbulence parameters.

Since 2012, the authors have been able to measure meteorological parameters using the acoustic mobile meteorological complex AMK-03. AMK-03 measures the following parameters: the projection of wind speed; wind direction; temperature; pressure; humidity; air density. In addition, the complex calculates the turbulence parameters: $\mathrm{u}^{*}$ - friction velocity, $\mathrm{m} / \mathrm{s}$; L - Monin - Obukhov scale, $\mathrm{m} ; \mathrm{H}$ - vertical heat flow, cal $/ \mathrm{m} 2 \mathrm{~s}$. Thus, it is possible to specify the settling velocity Vg. First, use the real density and dynamic viscosity of the air in the Stokes formula (1), from which Vg is calculated. First, use the real density and dynamic viscosity of the air in the Stokes formula (1), from which VG is calculated.

Thus, the data of the mobile complex AMK-03, in combination with the laws of dependence of the parameters of the boundary layer of the atmosphere, allow reasonably enough to calculate the rate of deposition of particles of different sizes $V_{\mathrm{dn}}$ on the underlying surface. A special research module embedded in the ERA software package (www.lpp/EN), automatiseret calculation $\mathrm{Vdn}$ in the acquisition of archives of observations of metalocomplex AMK-03. When performing calculations for a specific time, it is possible to calculate the $\mathrm{V}_{\mathrm{dn}}$ and set the coefficient $\mathrm{F}$ for these weather conditions.

The analysis of the calculations of dust particles deposition from atmospheric emissions with AMK-03 data (during which $\mathrm{V}_{\mathrm{dn}}$ is calculated for each observation) shows that for 
Kuzbass conditions $\mathrm{V}_{\mathrm{dn}}$ may differ from $\mathrm{V}_{\mathrm{g}}$ by $30 \%$ upwards and by $60 \%$ downwards. This can be taken into account in determining the actual subsidence factor $\mathrm{F}$ in tables 3 and 4 .

Zone influence determination of coal mining enterprises on air pollution with coal dust was carried out on the basis of the new methodology MRR-2017 [5]. The deposition rates for sources associated with mining processes in table 5 have been introduced uniformly for all enterprises in accordance with tables 1 to 4 .

By results of generalization of calculations of the indicator of $S_{p}$ for the coal mining enterprises of Kuzbass it is possible to allocate the following categories of the enterprises which influence coal mining on atmospheric air.
Category 1 (low impact)
$\mathrm{S}_{\mathrm{p}}<1.5$
Category 2 (moderate exposure) $1.5<\mathrm{S}_{\mathrm{p}}<2.5$;
Category 3 (severe impact) $\quad 2.5<\mathrm{S}_{\mathrm{p}}<3.5$;
Category 4 (hazardous effects) $3.5<\mathrm{S}_{\mathrm{p}}$.

Enterprises of the $3 \mathrm{rd}$ and especially the 4th category use environmentally imperfect coal mining technologies. On them first of all atmospheric protection actions (dust suppression, humidification, the closed points of loading, etc.), at the organization of processes of production, transportation, storage and shipment of coal have to be introduced.

Let us consider some examples of calculating the $S_{P}$ indicator based on data on sources of coal dust emissions for a number of open-pit coal mining enterprises in the Kemerovo region. Data on the first two sections are taken from departmental volumes of Maximum allowable physical impacts (MAPI) of the last years. For the rest of the summary volumes MAPI cities of Prokopyevsk, Kiselevsk, the Kemerovo and Mezhdurechensk developed in 2006-2008, OOO "Kuzbass environmental centre" (the authors express their gratitude to the Director of LLC T. G. Alekseichenko for the opportunity to use these data for scientific research). Data on coal production are taken for the years corresponding to the time of the inventory.

Table 6. Results of calculation of the indicator for some open-pit coal mining enterprises of the Kemerovo region.

\begin{tabular}{|c|c|c|c|}
\hline Enterprise & $\begin{array}{c}\text { Production } \mathbf{M}, \\
\text { thousand tons }\end{array}$ & $\begin{array}{c}\text { Area of influence, } \mathbf{S}, \\
\text { ha }\end{array}$ & $\begin{array}{c}\mathbf{S}_{\mathbf{p}}=\boldsymbol{S} / \boldsymbol{M}, \\
\text { ha/ thousand tons }\end{array}$ \\
\hline $\begin{array}{c}\text { Mine Uzhnaya }+ \\
\text { Chernigovec }\end{array}$ & 6174 & 2760 & 1,26 \\
\hline MM Mayskoe & 6654 & 4970 & 2,02 \\
\hline Oktyabrinskii & 250 & 672 & 2,72 \\
\hline Vahrushevskoe & 4115,7 & 5840 & 1,42 \\
\hline Prokopievskii & 1678,4 & 3930 & 2,34 \\
\hline Kiselevskii & 1905,8 & 4540 & 2,38 \\
\hline Tomusinskii & 2421 & 5761 & 2,37 \\
\hline Kedrovskii & 5040 & 12285 & 2,44 \\
\hline
\end{tabular}

\section{Conclusion}

The results of the calculation of the $\mathrm{S}_{\mathrm{P}}$ indicator are presented in table 6 . It is easy to see that for 6 of the 8 enterprises considered, the values of $S_{p}$ are quite close and lie in the range from 2.0 to 2.5 , which classifies them as moderate impacts on natural complexes and the population. 


\section{References}

1. A.A. Bykov, E.L. Schastlivtsev, Bulletin of the scientific center for safety in the coal industry, 1, 128-134 (2014)

2. Methodical manual on calculation, regulation and control of emissions of pollutants into the air (Research Institute of the Atmosphere, St. Petersburg, 2012)

3. A.A. Bykov, E.L. Schastlivtsev, S.G. Pushkin, A.V. Smirnov, Bulletin of polzunovskii, 2, 209-217 (2006)

4. About the approval of criteria of reference of the objects having negative impact on environment to objects I and II, in III and in IV categories (Government of the Russian Federation, Moscow, 2015)

5. About the approval of methods of calculation of dispersion of emissions of harmful (polluting) substances in atmospheric air (Government of the Russian Federation, Moscow, 2017)

6. Industry methodology for calculating the amount of waste, captured and emitted into the atmosphere of harmful substances by coal mining enterprises (Ministry of Energy o Russia, Moscow, 2003)

7. Guidance on risk assessment for public health of exposure to chemicals polluting the environment (Ministry of Energy o Russia, Moscow, 2004)

8. Sanitary protection zones and sanitary classification of enterprises, structures and other objects (Ministry of Energy o Russia, Moscow, 2014)

9. N.F. Tishchenko, Atmospheric air protection. Calculation of the content of harmful substances and their distribution in the air (Chemistry, Moscow, 1991)

10. M. L. Wesely, P.V. Doskey, J.D. Shannon, Deposition Parameterizations for the Industrial Source Complex (Argonne National Laboratory, Argonne, 2001) 